\title{
Replating of bioreactor expanded human bone marrow results in extended growth of primitive and mature cells
}

\author{
Bernhard $\varnothing$. Palsson ${ }^{1,2}$, Duk Jae $\mathrm{Oh}^{1}$ and Manfred R. Koller ${ }^{1,2}$ \\ ${ }^{1}$ Department of Chemical Engineering, University of Michigan, 3074 H.H. Dow Building, Ann Arbor MI \\ 48109-2136, USA; ${ }^{2}$ Aastrom Biosciences, Inc., P.O. Box 376, Ann Arbor, MI 48106, USA
}

Key words: Bioreactor, bone marrow, ex vivo expansion, perfusion culture, replating

\begin{abstract}
The capability to expand human bone marrow mononuclear cells (BM MNC) in high density perfusion culture chambers (bioreactors) has recently been developed. In these bioreactors, total cell colony-forming unitgranulocyte/macrophage (CFU-GM), and long-term culture-initiating cell (LTC-IC) numbers increase significantly over a 14-day period. However, cell growth ceases after the 14-day period, possibly due to cell density limitations. Because of the remaining presence of early cells, it should be feasible to replate the cells and obtain continued expansion. In this study, we demonstrate that bioreactors generate cells, which upon replating into secondary bioreactors, lead to continued cell, CFU-GM, and LTC-IC 8 (measured after 8 weeks of secondary culture) expansion. A two-stage protocol, involving the replating of cells on days 9 to 12 of culture into new bioreactors at the original seeding density, yielded greater than 50-fold cell expansion from BM MNC in 25 days. CFU-GM were expanded 11- to 12-fold and LTC-IC 8 numbers increased 6.3-fold over the same 25-day period. The addition of leukemia inhibitory factor (LIF) had no significant effect on total cells, CFU-GM, or LTC-IC 5 in this system. We conclude that two-stage bioreactor cultures are capable of supporting extended growth of human BM MNC, CFU-GM, and LTC-IC 8 . The continued expansion of these primitive cells in the second stage of culture suggests that primitive cells with significant proliferative potential were generated in this system, and previous data on $\mathrm{LTC}_{\mathrm{T}} \mathrm{IC}_{5}$ expansion has now been extended to LTC-IC 8 expansion. Further optimization of culture conditions is likely to improve on the results obtained here, thus making perfusion bioreactor culture correspondingly more attractive for expanding BM MNC for BM transplantation.
\end{abstract}

\section{Introduction}

In recent years, considerable interest has been focused on the expansion of human hematopoietic cells ex vivo (e.g. see Koller and Palsson, 1993). Successful culture systems would enable a variety of basic scientific and clinical studies in the fields of hematopoiesis and bone marrow (BM) transplantation. One attractive approach to accomplish this goal is the bioreactor culture of a small amount of aspirated BM resulting in expansion of total cell, CFU-GM, and LTC-IC numbers (Palsson et al., 1993; Koller et al., 1993). However, although these cultures generate significant numbers of cells after 14 days, the cell density reaches a plateau and little cell growth is obtained thereafter. Therefore, it appears that growth is limited by the cell density which can be supported by the current bioreactor design. Because the cells at that time contain primitive cells, it should be feasible to obtain further cell growth by removing some of the cells periodically, or by replating the cells onto a larger surface area (i.e. into many secondary bioreactors). Although periodic removal of cells has met with some degree of success (Oh et al., 1994), multiple disruptions of the cell bed is most likely undesirable in any clinical application. Therefore, one complete optimally-timed harvest and replating of all cells from the system might result in a more robust stimulus for growth, and may be more desirable in clinical practice. 
Replating of cultured hematopoietic cells into secondary cultures has been used as an indication of the primitive nature or self-renewal potential of cells (Terstappen et al., 1991; Carow et al., 1993). These types of experiments have been more successful with cord blood than with adult BM, suggesting that fewer cells in adult BM have self-renewal potential (Carow et al., 1993). These results have been confirmed and extended using primitive cell sorting, demonstrating that human fetal liver contains cells which are most proliferative upon replating, and that adult BM has a relatively low self-renewal potential (Lansdorp et al., 1993). Therefore, replating of bioreactor expanded adult BM should yield valuable information on the self-renewal potential of the cells which are generated under these conditions.

One factor which has recently been shown to affect primitive cell self-renewal is leukemia inhibitory factor (LIF). Several studies have suggested that in vivo repopulating murine cells are better maintained in the presence of LIF (Fletcher et al., 1991; Escary et al., 1993). In contrast, in vitro studies of purified human hematopoietic cells have shown a less dramatic effect of LIF (Verfaillie and McGlave, 1991; Brugger et al., 1993; Debili et al., 1993). Because LTC-IC analysis of two-stage bioreactor cultures offers a model to study primitive human cell self-renewal, we have also examined the effect of exogenous LIF in these studies.

\section{Materials and methods}

Cells Human BM was obtained from heparinized aspirates from the iliac crest of informed and consenting individuals. BM was separated by a FicollPaque (Pharmacia, Uppsala, Sweden) density gradient centrifugation, and the low density MNC in the interface band were collected and washed three times with Iscove's modified Dulbecco's medium (IMDM, GIB$\mathrm{CO}$, Grand Island, NY) as previously described (Koller et al., 1993).

Culture medium and hematopoietic growth factors The culture medium was IMDM containing $10 \%$ fetal bovine serum, $10 \%$ horse serum (Gibco), $1 \%$ penicillin/streptomycin $\left(10,000 \mathrm{U} \mathrm{ml}^{-1}\right.$ penicillin $\mathrm{G}$ and $10 \mathrm{mg} \mathrm{ml}^{-1}$ streptomycin), and $36 \mathrm{mM}$ sodium bicarbonate (Sigma, St. Louis, MO). Culture medium was supplemented with four growth factors: $2 \mathrm{ng}$ $\mathrm{ml}^{-1}$ interleukin-3 (IL-3, R \& D Systems, Minneapolis, MN), $5 \mathrm{ng} \mathrm{ml}^{-1}$ granulocyte-macrophage colony- stimulating factor (GM-CSF, Immunex, Seattle, WA), $0.1 \mathrm{U} \mathrm{ml}^{-1}$ erythropoietin (Epo, Amgen, Thousand Oaks, CA), and $10 \mathrm{ng} \mathrm{ml}^{-1}$ stem cell factor (SCF, c-kit ligand, Genzyme, Cambridge, MA). In one experiment, $5 \mathrm{ng} \mathrm{ml}^{-1}$ leukemia inhibitory factor (LIF, R\&D Systems) was added to the medium.

Bioreactor system and replating The bioreactor system used was comprised of a small cell culture chamber with continuous flow of medium as previously described (Palsson et al., 1993). In the first set of experiments, each of six bioreactors was inoculated with $4 \times 10^{6} \mathrm{BM} \mathrm{MNC}$. Three bioreactors were harvested on both days 10 and 12 . Harvested cells were counted and assayed for CFU-GM and LTC-IC. Cells from the three individual bioreactors were pooled and re-inoculated into ten new bioreactors at a cell density of $4 \times 10^{6}$ cells each. Two bioreactors, chosen randomly from the ten secondary bioreactors, were harvested every two days and cells were counted and analyzed for CFU-GM and LTC-IC.

In a second experiment, of nine reactors inoculated, six were harvested on day 9 ( 3 with and 3 without LIF) and three on day 11 (without LIF). The harvested cells from days 9 and 11 were replated into ten bioreactors as described above to measure extended growth. In addition, two sets of one-stage expansion controls were analyzed (six bioreactors). Six bioreactors (three with and three without LIF) were terminated on day 14. None of the control cultures were replated.

Cell harvest and colony assay Nonadherent cells were collected with a syringe by aspirating the medium contained in the bioreactor, which was followed by two washes of Hank's balanced saline solution (HBSS, GIBCO). Adherent cells were harvested by subsequent trypsinization for $20 \mathrm{~min}$, followed by a wash with medium. MNC were counted by an electronic cell counter (Coulter Electronics, Hialeah, FL) using a filtered aqueous solution containing $30 \mathrm{~g} \mathrm{l}^{-1}$ hexadecyl tri-methylammonium bromide (cetrimide, Sigma), $0.37 \mathrm{~g} \mathrm{l}^{-1}$ ethylenediaminetetraacetic acid (EDTA, Sigma), and $8.3 \mathrm{~g} \mathrm{l}^{-1} \mathrm{NaCl}$. CFU-GM density in the inoculated and harvested cell populations was enumerated with a two week colony assay. Cells from different nonadherent and adherent cell populations were suspended separately at a cell density of 2 $\times 10^{4}$ cells $/ \mathrm{ml}$ in methylcellulose medium (Terry Fox Labs, Vancouver, Canada) containing $2 \mathrm{U} \mathrm{ml}^{-1}$ Epo, 2 $\mathrm{ng} \mathrm{ml}{ }^{-1} \mathrm{IL}-3,5 \mathrm{ng} \mathrm{ml}^{-1} \mathrm{GM}-\mathrm{CSF}$, and $5 \mathrm{ng} \mathrm{ml}^{-1}$ granulocyte colony-stimulating factor (G-CSF; Neupogen, 

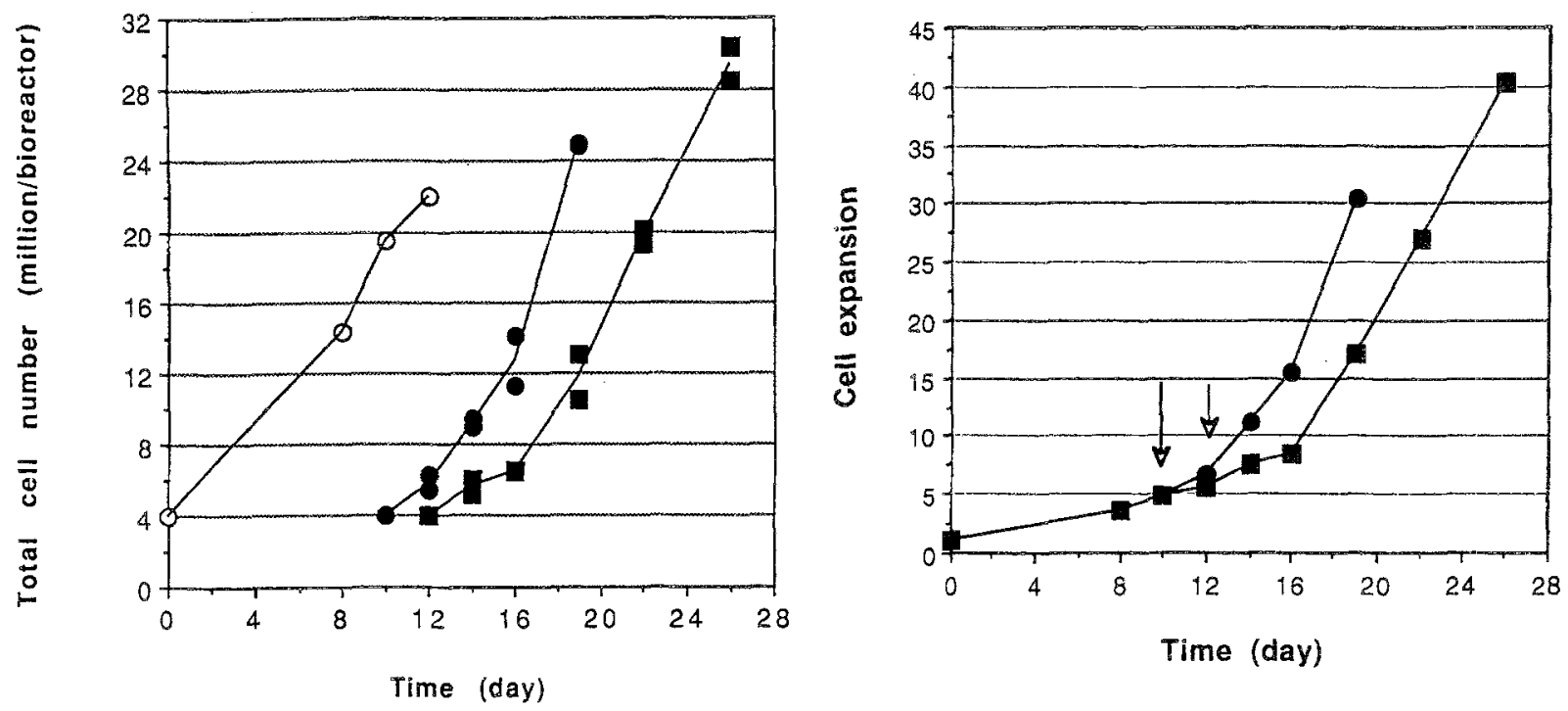

Fig. 1. Growth of human BM MNC in a two-stage perfusion bioreactor expansion culture. (a) Cells from first-stage bioreactors (open circles) were replated at days 10 (closed circles) and 12 (closed squares) into ten new bioreactors, and these were harvested at two to three day intervals thereafter. (b) Total cell numbers obtainable from the initial 4 million cell inoculum were calculated by adjusting for the cell split at the day of replating. The arrows indicate the time of replating.

Amgen). After 14 days in a humidified $5 \% \mathrm{O}_{2}$ and $5 \%$ $\mathrm{CO}_{2}$ incubator, colonies of greater than 50 cells were scored.

Long-term culture-initiating cell (LTC-IC) assay For enumeration of LTC-IC in the inoculated and harvested cell populations, limiting dilution assay (LDA) was used (Sutherland et al., 1990) as previously described (Koller et al., 1993). LTC-IC cultures were carried for either five ( $\mathrm{LTC}_{\mathrm{IC}}$ ) or eight weeks (LTC-IC $\mathrm{IC}_{8}$ ). LTC$\mathrm{IC}_{8}$ are thought to be more primitive than $\mathrm{LTC}_{-} \mathrm{IC}_{5}$ because they are less frequent in marrow (Sutherland et al., 1990) and appear to be more resistant to 4-HC (Winton and Colenda, 1987). Cells were plated on irradiated stromal layers at concentrations from 1 to $5 \times 10^{4}$ cells per well in a 96-well culture plate $(20$ replicates per concentration). The plates were placed in a fully humidified $33{ }^{\circ} \mathrm{C}, 5 \% \mathrm{CO}_{2}$ incubator, and the cultures were fed weekly by replacing $50 \%$ of the medium. After either five or eight weeks of culture, cells were harvested from each well by trypsinization, then washed with HBSS and added to $0.25 \mathrm{ml}$ of colony assay medium in 24-well plates. Colonies were scored by the colony assay protocol described above. For each sample, the number of LTC-IC was determined through an iterative calculation procedure
(De St. Groth, 1982) based on the maximum likelihood method (Finney, 1951). Confidence intervals were calculated as described (De St. Groth, 1982) and are shown on Figs. 3 and 6.

\section{Results}

Two-stage expansion of bone marrow in bioreactors Six bioreactors were inoculated with 4 million BM MNC each. Three bioreactors were harvested on days 10 and 12 , and at both times, cells were pooled and inoculated into ten new bioreactors at 4 million cells each. Cells in excess of the 40 million required to inoculate the ten bioreactors were discarded. During the second expansion period, two bioreactors were harvested every two days to generate the extended growth curve. In the first stage, the cells expanded approximately 5 - and 6 -fold by days 10 and 12 , respectively (Fig. 1a). After replating, the cells continued to expand, reaching over 25 million cells per bioreactor at the last time point examined. If all ten of the bioreactors used during the second expansion period had been harvested on the last day, the overall cell expansion would have been 30 -fold (10 day series) and 40-fold (12 day 


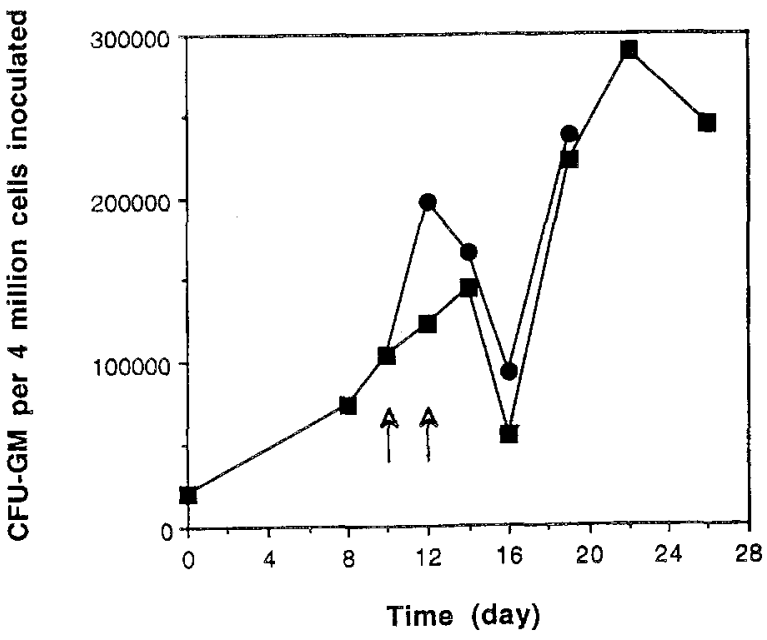

Fig. 2. The number of CFU-GM produced in a two-stage perfusion bioreactor expansion culture. Experimental conditions are as in Fig. 1. Total CFU-GM numbers obtainable from the initial 4 million cell inoculum were calculated by adjusting for the cell split at the day of replating. The arrows indicate the time of replating. Circles denote day 10 replating series and squares denote day 12 replating series.

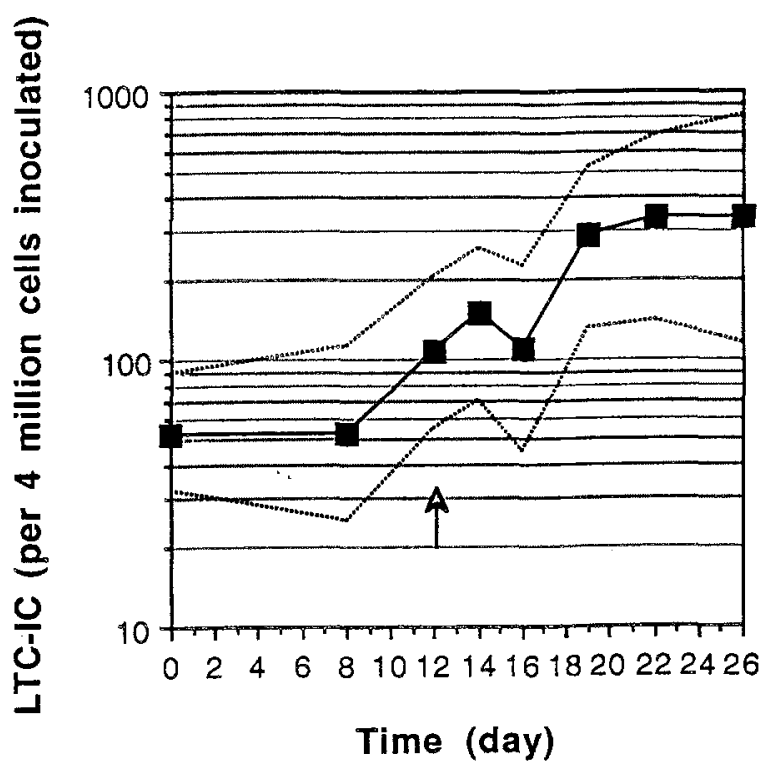

Fig. 3. The number of LTC-IC 8 produced in a two-stage perfusion bioreactor expansion culture. Experimental conditions are as in Fig. 1. Total LTC-IC 8 numbers obtainable from the initial 4 million cell inoculum were calculated be adjusting for the cell split at the day of replating. The arrow indicates the time of replating. Dashed lines correspond to a $95 \%$ confidence interval based on the maximum likelihood solution method [15]. series). This observation, which adjusts for the cell split on the day of replating, is reflected in Fig. 1b.

The number of CFU-GM (per 4 million cells initially inoculated) increased until day 10 to give a 5.1-fold expansion (Fig. 2). After replating on day 10, CFU-GM numbers increased further to give a 9.7-fold expansion by day 12 , but then declined on days 14 and 16 . In a similar fashion, after replating on day 12, CFU-GM numbers increased further to give a 7.3-fold expansion by day 14 , but then declined on day 16 . After day 16, CFU-GM numbers increased dramatically in both groups, resulting ultimately in a greater than 14-fold expansion of CFU-GM.

In this experiment, the number of primitive LTC$\mathrm{IC}_{8}$ were enumerated at several time points of the day 12 series (Fig. 3). LTC-IC 8 were expanded 2-fold by day 12 of culture. After replating, LTC-IC 8 numbers continued to increase, resulting in a total 6.3-fold expansion $(p<0.05)$ over the two-stage culture period.

Effect of exogenous LIF on two-stage bioreactor cultures In the second series of experiments, cells were replated as described above, except in three experimental groups; two at day 9 and one at day 11 . One of the two day 9 groups contained LIF in addition to the standard four growth factors (IL-3, GM-CSF, $\mathrm{SCF}$, and Epo). In addition to the experimental groups that were replated, triplicate control one-stage cultures were examined at day 14 (with and without LIF) as points of reference. Cell expansion was similar to that obtained in the first series of experiments (Fig. $4 \mathrm{a}$ ). The one-stage controls generated about 42 million cells per bioreactor by day 14 . All two-stage cultures expanded cells before and after replating, resulting in approximately 30 million cells per bioreactor at the last time point examined. The extended growth curve, adjusted for the cell split at replating, shows that greater cell expansion was obtained in two-stage cultures than in one-stage cultures (Fig. 4b). For example, one-stage cultures generated 10.5 -fold cell expansion by day 14 (open triangles, Fig. 4b), whereas two-stage cultures resulted in 40-fold cell expansion at day 21 and nearly 60 -fold by day 27 . The increase in cell growth area provided by the replating procedure thus allowed the cells to continue expanding beyond the limitations imposed by the one-stage expansion protocol. There did not appear to be a significant effect of exogenous LIF on the cell expansion data.

CFU-GM numbers, adjusted for the cell split at replating, showed a similar pattern as in the prior 

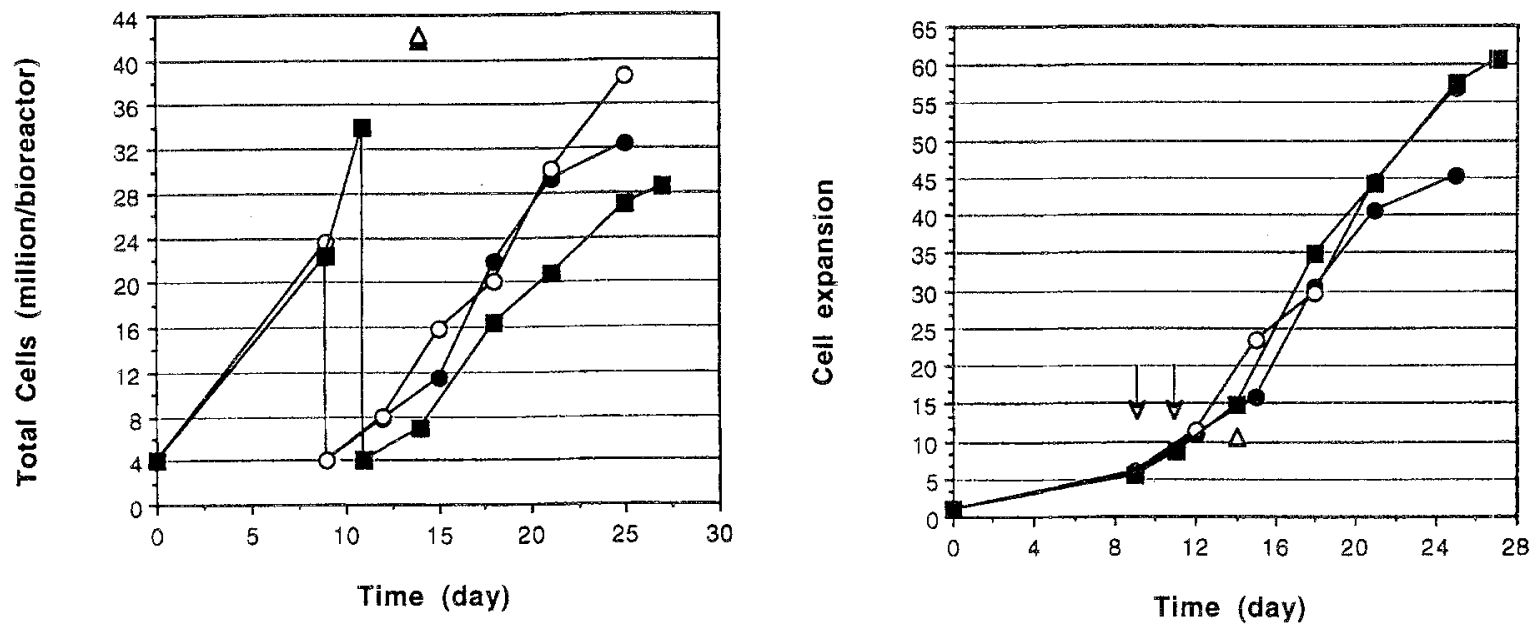

Fig. 4. Effect of LIF on the growth of human BM MNC in a two-stage perfusion bioreactor expansion culture. (a) Cells from first-stage bioreactors were replated at days 9 (circles) and 11 (squares) into ten new bioreactors, and these were harvested at two to three day intervals thereafter. Bioreactors with LIF were also examined with the day 9 replating protocol (open circles). Control one-stage bioreactors were examined at day 14 with and without LIF (small solid and open triangles, respectively). (b) Total cell numbers obtainable from the initial 4 million cell inoculum were calculated by adjusting for the cell split at the day of replating. The arrows indicate the day of replating.

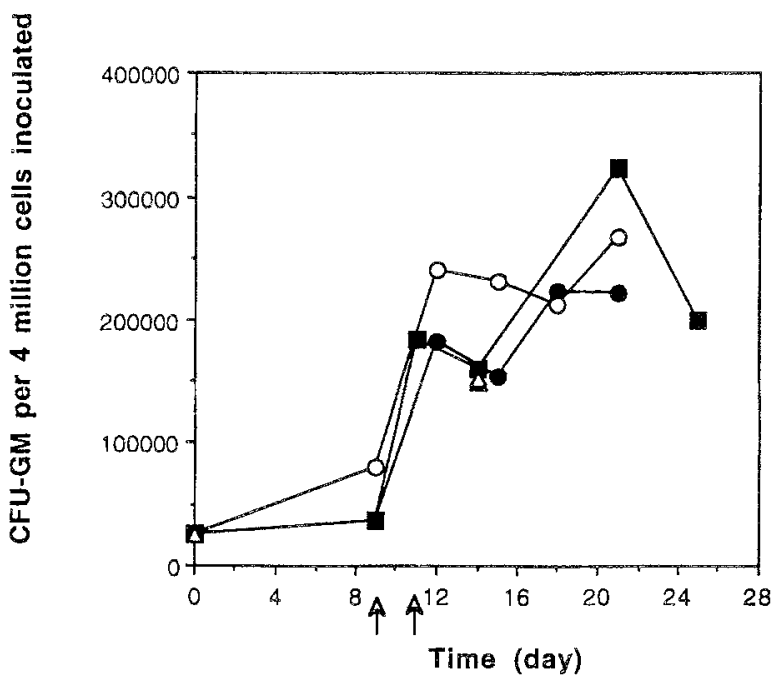

Fig. 5. Effect of LIF on the number of CFU-GM produced in a two-stage bioreactor expansion. Experimental conditions and symbols are as in Fig. 4. Total CFU-GM numbers obtainable from the initial 4 million cell inoculum were calculated by adjusting for the cell split at the day of replating. The arrows indicate the time of replating.

experiment (Fig. 5). CFU-GM numbers increased until day 12 , then declined briefly several days after replating, and then continued increasing at later time points.
Although the number of CFU-GM obtained on day 14 was similar in the one- and two-stage cultures, twostage cultures continued to expand CFU-GM numbers beyond day 14, whereas one-stage cultures typically exhibit a decline in CFU-GM numbers following day 14 (e.g. see Palsson et al., 1993). This demonstrates that the two-stage expansion protocol allowed expansion of progenitors beyond the cell growth area limitations imposed by the one-stage expansion protocol.

LTC-IC $_{5}$ were enumerated in the inoculum and at the time of replating (Fig. 6). Unfortunately, LTC-IC data were not obtained during the second expansion stage. LTC-IC $_{5}$ expanded 2- to 3-fold during the first 9 to 11 days of culture, which is consistent with the data presented above and our previously published data (Koller et al., 1993). LIF did not significantly increase the number of LTC-IC 5 generated by day 9 .

\section{Discussion}

High cell density bioreactor cultures of BM MNC have demonstrated the expansion of total cell, CFU-GM, and $\mathrm{LTC}-\mathrm{IC}_{5}$ numbers over a 14-day cultivation period (Palsson et al., 1993; Koller et al., 1993). However, the cell density reaches a plateau after about 14 


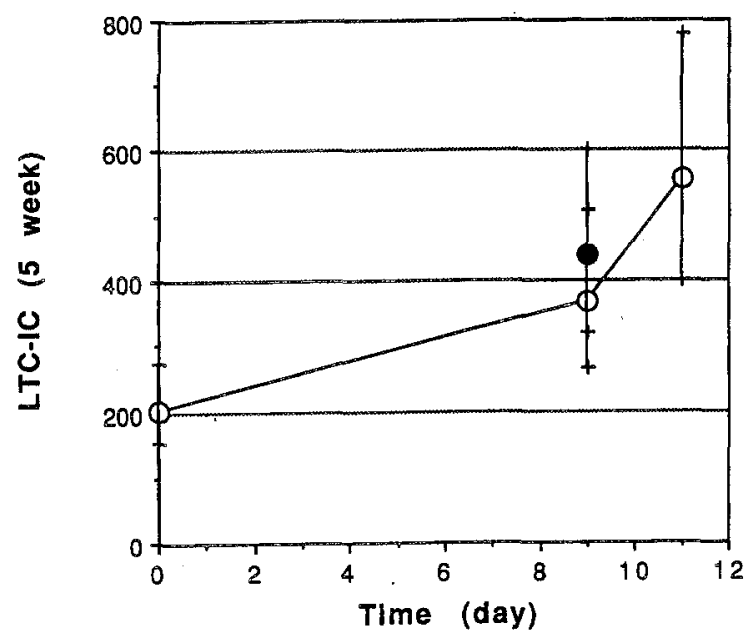

Fig. 6. Effect of LIF on the number of LTC-IC 5 produced in a perfusion bioreactor expansion system. Experimental conditions and symbols are as in Fig. 4.

days and little additional growth is obtained thereafter. Because of the remaining presence of early cells, it should be feasible to replate the cells and obtain continued expansion. In this study, we demonstrate that bioreactor cultures generate cells, which upon replating into secondary bioreactors, lead to continued cell, CFU-GM, and $\mathrm{LTC}-\mathrm{IC}_{8}$ expansion. In addition, we demonstrate that the addition of exogenous LIF at $5 \mathrm{ng}$ $\mathrm{ml}^{-1}$ to the other four growth factors used (IL-3, GMCSF, SCF, and Epo) did not have a significant effect on the cell parameters measured in this study.

The results obtained through the single replating procedure further demonstrate that bioreactor cultures are capable of retaining early cells while expanding their progeny. Significant increases in both total cells and CFU-GM were obtained in the two-stage cultures as compared with the one-stage cultures. The LTC$\mathrm{IC}_{5}$ expansion results after the first stage of culture are consistent with our earlier published results (Koller $e t$ al., 1993). Because LTC-IC $C_{8}$ are thought to be more primitive than $\mathrm{LTC}^{-\mathrm{IC}_{5}}$ (Sutherland et al., 1990; Winton and Colenda, 1987), the LTC-IC 8 expansion results extend the earlier expansion results to a more primitive cell type. Furthermore, the continued expansion of these primitive cells in the second stage of culture suggests that primitive cells with significant proliferative potential were generated in this system. It is interesting that the number of $\mathrm{LTC}^{-\mathrm{IC}_{8}}$ did not increase until after day 8 , whereas $\mathrm{LTC}^{-\mathrm{IC}_{5}}$ appeared to increase earlier. One possible interpretation of these data is that a small subset of stem cells were committed to differentiation upon inoculation, followed by some selfrenewal in that compartment. Upon replating, there was an increase in CFU-GM number, followed by a decrease, and then another large increase. It appears that replating caused activation of early cells which required several days to appear in the CFU-GM compartment. This activation, which resulted in a second wave of cell growth without loss of primitive cells, did not occur without replating. These observations may be compared with reports noting that a few days are required for stem cells to enter cell cycle after the initiation of culture. For instance, it has been reported that highly purified early cells (CD34+ CD $45 \mathrm{RA}^{\text {lo }} \mathrm{CD} 71^{\text {lo }}$ ) require $60 \mathrm{~h}$ of culture before the first division takes place (Denkers et al., 1993).

The extended growth potential of bioreactorexpanded cells has also been demonstrated by frequent harvesting of a high fraction of non-adherent and adherent cells (Oh et al., 1994). When only nonadherent cells are removed, the extended expansion of progenitor cells is limited. These results are thus consistent with the observation reported here; that disruption of the association between stroma and primitive cells, followed by replating at the original cell density, results in increased production of all cell types over time. One feature of this two-stage protocol is the continued growth of autologous stroma in the bioreactors without attainment of complete confluence. This continuously growing stroma may be one factor which drives the continuous expansion of LTC-IC. Consistent with this concept are reports showing that liquid cultures of selected $\mathrm{CD} 34^{+}$cells, which do not allow for stromal cell growth, do not expand or maintain LTC-IC (Sutherland et al., 1991, 1993; Verfaillie, 1992; Koller et al., 1995a).

Our results indicate that exogenous LIF had no significant effect on total cells, CFU-GM, or $\mathrm{LTC}^{-\mathrm{IC}_{5}}$ in this system. Although previous studies have suggested that in vivo repopulating murine cells are better maintained in the presence of LIF (Fletcher et al., 1991; Escary et al., 1993), in vitro studies of purified human hematopoietic cells have shown a less dramatic effect of LIF (Verfaillie and McGlave, 1991; Brugger et al., 1993; Debili et al., 1993). Because of the presence of accessory cells and stroma in these bioreactors, endogenous production of LIF may overshadow any effects of exogenous LIF. In fact, we have evidence that LIF is endogenously produced in these cultures, 
although at relatively low levels of $<50 \mathrm{pg} \mathrm{ml}^{-1}$, (Koller et al., 1995b).

The results presented here indicate that perfusion bioreactors support a limited number of cells, after which little growth occurs. A number of factors could limit the maximum cell density attained in these cultures. One such factor is simply the size of the cell growth area. After 14 days, the growth surface becomes completely covered with a layer of cells at least $4-6$ cells deep. This may result in contact inhibition of certain cell types, or in nutrient or oxygen limitation within the cell bed. These and other considerations have been discussed elsewhere in detail (Koller and Palsson, 1993). It is therefore likely that further optimization of bioreactors for hematopoietic cell growth will result in improved culture performance.

\section{References}

Brugger W, Möcklin W, Heimfeld S, Berenson RJ, Mertelsmann $\mathrm{R} \&$ Kanz L (1993) Ex vivo expansion of enriched peripheral blood $\mathrm{CD} 34^{+}$progenitor cells by stem cell factor, interleukin-1 $\beta$ (IL-1 $\beta$ ), IL-6, IL-3, interferon- $\gamma$, and erythropoietin. Blood 81 : 2579-2584.

Carow CE, Hangoc G \& Broxmeyer HE (1993) Human multipotential progenitor cells (CFU-GEMM) have extensive replating capacity for secondary CFU-GEMM: An effect enhanced by cord blood plasma. Blood 81: 365-372.

Debili N, Massé J-M, Katz A, Guichard J, Breton-Gorius J \& Vainchenker W (1993) Effects of the recombinant hematopoietic growth factors interleukin-3, interleukin-6, stem cell factor, and leukemia inhibitory factor on the megakaryocytic differentiation of CD34+ cells. Blood 82: 84-95.

Denkers AM, Dragowska W, Jaggi B, Palcic B \& Lansdorp PM (1993) Time lapse video recordings of highly purified human hematopoietic progenitor cells in culture. Stem Cells 11: 243 248.

De St. Groth SF (1982) The evaluation of limiting dilution assays. J. Immunol. Meth. 49: R11-R23.

Escary J-L, Perreau J, Duménil D, Ezine S \& Brûlet P (1993) Leukaemia inhibitory factor is necessary for maintenance of haematopoietic stem cells and thymocyte stimulation. Nature 363: 361-364.

Finney DJ (1951) The estimation of bacterial densities from dilution series. J. Hygiene 49: 26-35.

Fletcher FA, Moore KA, Ashkenazi M, DeVries P, Overbeek PA, Williams DE \& Belmont JW (1991) Leukemia inhibitory factor improves survival of retroviral vector-infected hematopoietic stem cells in vitro, allowing efficient long-term expression of vector-encoded human adenosine deaminase in vivo. J. Exp. Med. 174: 837-845.
Koller MR \& Palsson BØ (1993) Tissue engineering: Reconstitution of human hematopoiesis ex vivo. Biotechnol. Bioeng. 42: 909930.

Koller MR, Emerson SG \& Palsson BØ (1993) Large-scale expansion of human stem and progenitor cells from bone marrow mononuclear cells in continuous perfusion culture. Blood 82 : 378-384.

Koller MR, Palsson MA, Manchel I \& Palsson B $\emptyset$ (1995a) Longterm Culture-Initiating cell expansion is dependent on frequent medium exchange, combined with stromal and other accessory cell effects. Blood, in press.

Koller MR, Bradley MS \& Paisson BØ (1995b) Growth factor consumption and production in perfusion cultures in human bone marrow correlates with specific cell production. Exp. hematol., in press.

Lansdorp PM, Dragowska W \& Mayani H (1993) Ontogeny-related changes in proliferative potential of human hematopoietic cells. J. Exp. Med. 178: 787-791.

Oh D-J, Koller MR \& Palsson BØ (1994) Frequent harvesting from perfused bone marrow cultures results in increased overall cell and progenitor expansion. Biotech. and Bioeng. 44: 609-616.

Palsson BØ, Paek S-H, Schwartz RM, Palsson M, Lee G-M, Silver $S$ \& Emerson SG (1993) Expansion of human bone marrow progenitor cells in a high cell density continuous perfusion system. Bio/Technology 11: 368-372.

Sutherland HJ, Lansdorp PM, Henkelman DH, Eaves AC \& Eaves CJ (1990) Functional characterization of individual human hematopoietic stem cells cultured at limiting dilution on supportive marrow stromal layers. Proc. Natl. Acad. Sci. USA 87: 3584-3588.

Sutherland HJ, Eaves CJ, Lansdorp PM, Thacker JD \& Hogge DE (1991) Differential regulation of primitive human hematopoietic stem cells in long-term cultures maintained on genetically engineered murine stromal cells. Blood 78: 666-672.

Sutherland HJ, Hogge DE, Cook D \& Eaves CJ (1993) Alternative mechanisms with and without steel factor support primitive human hematopoiesis. Blood 81: 1465-1470.

Terstappen LWMM, Huang S, Safford M, Lansdorp PM \& Loken MR (1991) Sequential generations of hematopoietic colonies derived from single nonlineage-committed $\mathrm{CD} 34^{+} \mathrm{CD} 38^{-}$progenitor cells. Blood 77: 1218-1227.

Verfaillie C \& McGlave P (1991) Leukemia inhibitory factor/human interleukin for DA cells: a growth factor that stimulates the in vitro development of multipotential human hematopoietic progenitors. Blood 77: 263-270.

Verfaillie CM (1992) Direct contact between human primitive hematopoietic progenitors and bone marrow stroma is not required for long-term in vitro hematopoiesis. Blood 79: 28212826.

Winton EF \& Colenda KW (1987) Use of long-term human marrow cultures to demonstrate progenitor cell precursors in marrow treated with 4-hydroperoxycyclophosphamide. Exp. Hematol. 15: $710-714$.

Address for correspondence: Bernard O. Palsson, Ph.D., Department of Chemical Engineering, University of Michigan, Ann Arbor, MI 48109-2136, USA. 